\title{
Usefulness of Chlamydia serology in prediction of tubal factor infertility among infertile patients at Federal Medical Centre, Bida, North Central Nigeria
}

\author{
Lucky Amadi', Uchenna Onwudiegwu ${ }^{2}$, Adebanjo B. Adeyemi², \\ Chiemezie N. D. Nwachukwu ${ }^{1}$, Afolabi B. Abiodun ${ }^{3 *}$
}

\author{
${ }^{1}$ Department of Obstetrics and Gynecology, Federal Medical Centre, Bida, Niger State, Nigeria \\ ${ }^{2}$ Department of Obstetrics and Gynecology, Obafemi Awolowo University Teaching Hospital Complex Ile-ife, Osun \\ State, Nigeria \\ ${ }^{3}$ Department of Family Medicine, Subol Hospital Limited, Idimu, Lagos, Nigeria
}

Received: 21 November 2018

Accepted: 29 December 2018

\section{*Correspondence:}

Dr. Afolabi B. Abiodun,

E-mail: abiodunben@yahoo.com

Copyright: ( ) the author(s), publisher and licensee Medip Academy. This is an open-access article distributed under the terms of the Creative Commons Attribution Non-Commercial License, which permits unrestricted non-commercial use, distribution, and reproduction in any medium, provided the original work is properly cited.

\begin{abstract}
Background: Infertility is a major public health problem in developing countries where pelvic inflammatory disease due mainly to Chlamydia trachomatis and Neisseria gonorrhea infection have been implicated. The role of Chlamydia serology in predicting tubal factor infertility (TFI) has been demonstrated by many researchers elsewhere. However, there are limited data in our environment. This prospective cross-sectional study aims to determine the usefulness of Chlamydia Serology as a screening tool for TFI at Federal Medical Centre, Bida, North Central Nigeria.

Methods: 125 women with infertility who met the inclusion criteria were enrolled into the study. Relevant information on their socio-demographic characteristics, gynaecological symptoms and risks factors for infertility were obtained. Participants had Hysterosalpingography (HSG) as part of their fertility work-up while $5 \mathrm{ml}$ of venous blood was withdrawn to check for Immunoglobulin G antibody to Chlamydia trachomatis using rapid test kits. The HSG findings were correlated with the result of Chlamydia serology. Data was analyzed using the computer software, Statistical Package for Social Science (SPSS) version 20. The level of significance (p value) was set at 0.05.

Results: A total of 120 infertile women completed the study, 5 had incomplete investigations and were excluded from the analysis. The prevalence of TFI was $47.5 \%$, while that of positive chlamydia serology was $36.5 \%$. The prevalence of chlamydial seropositivity was $59.6 \%$ for patients with TFI but $15.9 \%$ for non-TFI. There was a significant association between positive chlamydia serology and TFI $\mathrm{p}<0.05$. The study revealed moderate sensitivity $59.6 \%$, and negative predictive value $69.7 \%$ but high specificity $84.1 \%$ and positive predictive value of $77.2 \%$. In this study the odds for diagnosing tubal infertility was 7.8.

Conclusions: Chlamydia serology is useful in predicting TFI and should be incorporated in the routine work up for infertility.
\end{abstract}

Keywords: Bida, Chlamydia serology, Tubal Infertility

\section{INTRODUCTION}

Infertility is the inability of a couple of childbearing age to achieve a pregnancy over twelve months of regular, unprotected sexual intercourse. ${ }^{1}$ Infertility causes great distress to many couples, causing increasing numbers of them to seek specialist fertility care. ${ }^{2}$ It places a huge psychological burden on the infertile couple, especially 
on the woman and it may lead to depression, suicidal tendencies, and other pathologic psychological conditions. $^{3}$

The incidence of the causes of infertility is generally believed to be equally distributed among men and women. In Africa, about $40 \%$ of infertility cases are attributed to male factors, while another $40 \%$ are due to female factors, $15 \%$ combined male/female factors and $5 \%$ is unexplained infertility. ${ }^{4}$

The most common cause of tubal factor infertility is occlusion of the fallopian tubes due to an infection that is sexually transmitted, by Chlamydia trachomatis or Neisseria gonorrhea. ${ }^{5}$ Persistent tubal infections by $C$. trachomatis are also a common feature.

In sub-Saharan Africa, Sharma et al found that sexually transmitted diseases (STDs) are responsible for more than $70 \%$ of cases of pelvic infections, with most being caused by Chlamydia and $N$. gonorrhea ${ }^{6}$ Chlamydia infection is indolent and may remain unrecognized until screening is done.

In Nigeria, Omo-Aghoja et al found that the prevalence of serum Chlamydia antibody was $65.8 \%$ in women with tubal factor infertility. ${ }^{7}$ However, Moharson-Bello in South west Nigeria found a prevalence of Chlamydia trachomatis infection to be $20.5 \%$ and positively predict tubal blockage. ${ }^{8}$ Tukur et al in Northwest Nigeria found a prevalence of Chlamydia trachomatis infection to be $88.7 \%$. They also found a significant association between genital Chlamydia infection with the tubal factor infertility. ${ }^{9}$ The foregoing shows that there is possibility of geographical variation in prevalence, justifying the need to evaluate North central Nigeria.

For years, culture of the organism was the only recommended technique, for chlamydial diagnosis and has been regarded as the gold standard method with which other methods will be compared. Cell culture technique has excellent specificity but low sensitivity. ${ }^{10}$ The non-culture techniques are now proving to be effective with good specificity and sensitivity especially the enzyme immunoassays (EIA) which uses monoclonal or polyclonal antibodies against the major outer membrane protein (MOMP) or the lipopolysaccharides (LPs) of C. trachomatis. ${ }^{1}$

Chlamydia trachomatis is a non-motile, small Gramnegative bacterium that is an obligate intracellular parasite transmitted sexually or vertically. ${ }^{11}$ Chlamydia trachomatis infection can be detected by cell culture or detection of antigen for recent infection or serology for chronic infection. ${ }^{12}$

The two most important diagnostic procedures that are used for evaluation of tubal patency are hysterosalpingography (HSG) and laparoscopy and both are complementary. ${ }^{13}$ It has been shown by several studies that previous Chlamydial trachomatis infection is a strong risk factor for the development of tubal factor infertility. ${ }^{5,8,9}$ It therefore stands to reason that Chlamydia serology may be necessary aspect of screening for infertile women and may also serve as a pointer to those that might require further evaluation for tubal factor infertility. Africa shares the largest burden of infertility in the World. ${ }^{14}$ Estimates indicate that an average of $10.1 \%$ of couples experience infertility in Africa, with a high percentage of $32 \%$ in some countries and ethnic groups within Africa. ${ }^{14}$ The World Health Organization estimates that up to $64 \%$ of infertility cases in Africa are attributable to genital tract infections in males and females as compared to other regions of the world. ${ }^{15}$ The CDC has shown that of these STIs, Chlamydia trachomatis is the most common, usually asymptomatic, but quite damaging to the fallopian tubes. ${ }^{16}$

Several studies have shown that tubal infertility can be predicted with high degree of accuracy using chlamydial serology. ${ }^{17-19}$ Surana et al found $60 \%$ seropositivity and $52 \%$ of them showed bilateral tubal blockage. Debakausen et al showed that $C$. trachomatis serology was superior to HSG in predicting tubal factor infertility. ${ }^{18}$ HSG and laparoscopy are the two main methods of assessing tubal patency and they are both complementary. However, they are invasive and expensive. ${ }^{20}$ The sensitivity and positive predictive value of Chlamydia serology in detecting tubal pathology among women with infertility is however comparable with that of HSG. ${ }^{21,22}$

The study therefore aims to determine the usefulness of Chlamydia serology in predicting tubal factor infertility among infertile women in FMC, Bida, North central Nigeria.

\section{METHODS}

The study was conducted at the gynaecologic clinic of FMC, Bida. The hospital is located in Niger State, North central Nigeria. The hospital was established in 1927 by the Colonial Masters and it was serving the then middle belt and later a general hospital in Niger State. It was upgraded to a tertiary health institution in 1997. It is the biggest tertiary health care centre in Niger State and its environment. There are two gynaecology clinic days in a week: Mondays and Thursdays. The gynaecology clinic attendees are about 1,500 per annum over $40 \%$ of which are infertility cases, making average monthly attendance of 50 infertility cases. This was a prospective crosssectional study. The study population comprised women with primary and secondary infertility attending gynaecological clinics at the FMC, Bida, Niger state.

\section{Inclusion criteria}

- Women with infertility

- Consent to participate in the study. 


\section{Exclusion criteria}

- Women who had achieved pregnancies within the past 12 months irrespective of pregnancy location

- Women who did not give consent to participate in the study

- Women who have had pelvic or tubal surgeries

- Women with history suggestive of endometriosis.

The minimum sample size was estimated using the Kish Leslie's formula for single proportions. ${ }^{23}$

$\mathrm{n}=\underline{\mathrm{z}^{2}} \mathrm{p}(\mathrm{I}-\mathrm{p})$

$d^{2}$

$\mathrm{n}=$ minimum sample size

$\mathrm{Z}=$ represents the desired level of statistical significance which is equivalent to 1.96 for a $95 \%$ confidence interval.

$\mathrm{p}=$ proportion of women with infertility secondary to chlamydia infection $(0.08)^{24}$

$\mathrm{d}=$ level of acceptable error which is set at $5 \%$.

$\mathrm{n}=\underline{1.96^{2}(0.08)(1-0.08)}$

$0.05^{2}$

$\mathrm{n}=113$ Subjects.

Allowing a non-response rate of $10 \%$, a minimum sample size of 125 was used for this study.

Sequential enrolment was employed for the selection of the study subject from the study population till the desired sample size was achieved. The study subjects were consecutively selected from women diagnosed with primary and secondary infertility at the gynaecology clinics of the hospital.

One hundred and twenty-five patients with primary and secondary infertility diagnosed at the gynaecology clinic from clinical history and examination findings were selected. After giving their informed consent, a purposedesigned proforma was used to obtain the sociodemographic data, gynaecologic history and other relevant information. Hysterosalpingography, using urograffin on the $10^{\text {th }}$ day of the menstrual cycle was performed on all the patients as part of their routine evaluation to determine their tubal status. Other routine investigations such as midluteal phase progesterone for ovulatory test and husbands' seminal fluid analyses were done to rule out male factor infertility as per departmental protocol. Serum samples were obtained to detect chlamydia antibodies IgG using the gold immunefiltration anti-Chlamydia IgG rapid test Kit produced by Span biotech limited, China. ${ }^{25}$

\section{Anti-Chlamydia IgG test}

The sample was obtained, and the procedure carried out according to the manufacturer's instruction. Five millilitre of venous blood was withdrawn from the patients into a plain bottle. The blood was allowed to clot and retract, following which the supernatant (serum) was carefully removed with a micropipette. Two drops of the wash buffer were added into the hole of the Kit and allowed to soak the membrane completely and 50 $\mu 1$ of the serum was added into the hole on the kit and allowed to absorb, then 3 drops of colloidal conjugate was added into the hole and allowed to absorb. Lastly 3 drops of the wash buffer was added and the result was read within 3 minutes.

\section{Interpretation of results}

The presence of only one pink line on the control region with none on the test region was interpreted as a negative result while the presence of an additional distinct pink line on the test region meant a positive result. The result was invalid if there was total absence of pink line in both test and control regions or there was no pink line on the control region signifying a procedural error. The rapid tests employ enzyme immunoassay technology, which involves immunohistochemical detection of antigen using enzyme labelled monoclonal or polyclonal antibodies. The result of hysterosalpingography was interpreted such that bilateral tubal blockage was considered as tubal factor infertility. One or both patent tubes qualified the patient as non-tubal infertility.

\section{Sensitivity/specificity of the kit}

The reported sensitivity of the anti-Chlamydia IgG rapid Kit that was used in this study was $98 \%$ and specificity was $98 \% .^{25}$ These results were comparable to ELISA Kits; however, the limitation of the rapid Kit test is that the results are qualitative.

\section{Statistical analysis}

Data obtained at the end of this study was processed using the computer software, Statistical Package for Social Science (SPSS) version 20 after cleaning. Descriptive analysis was done for quantitative variables by calculating relevant means and standard deviations while qualitative variables were analyzed using proportions. Presentations of these were made in appropriate tables and figures. Continuous variables were tested for statistical significance using the student t-test while Pearson Chi square (or Fishers Exact Test of significance in cases when an expected cell count is less than five) was used for categorical variables. Level of significance was set at 0.05 .

All participants were duly informed about the study and reserved the right to voluntarily withdraw for whatever 
reasons without penalty. A written informed consent was obtained from each of the participants.

\section{RESULTS}

A total of 125 infertile women were enrolled into the study over a period of four months (SeptemberDecember). Five of the subjects did not have complete investigations and were excluded from the analysis. Two of the participants have no HSG result, while three of the spouses refused to have seminal fluid analysis done because they had other wives that had children.

The women's ages ranged between 20-45 years, mean of $31.8 \pm 5.3$ years as shown in Table 1. The other relevant demographic and clinical variables are as shown in Table 1.

More than two-thirds, $84(70.0 \%)$ of the subjects belonged to middle or low socioeconomic class and the association between low socio-economic status and chlamydial serology was statistically significant $(\mathrm{p}=0.04)$ as shown in Table 2. The other relevant significant risk factors for chlamydia seropositivity such as parity and young age at first sexual intercourse were also highlighted in Table 2. Secondary infertility contributed the larger entity $76(64.3 \%)$ while the mean duration of infertility was $5.5 \pm 4.5$ years. About three-quarters, 76 $(62.7 \%)$ had previous history of pelvic infections of which $43(35 \%)$ got treated.

Table 1: Baseline demographic and clinical data.

\begin{tabular}{|l|l|l|l|l|l|}
\hline Characteristics & N & Minimum & Maximum & Mean & Standard deviation \\
\hline Age & 120 & 20.00 & 45.0 & 31.8 & 5.3 \\
\hline Age at first sexual intercourse & 120 & 8.00 & 34.0 & 19.8 & 4.9 \\
\hline Parity & 120 & 0.00 & 3.0 & 1.4 & 1.0 \\
\hline Lifetime number of sexual partners & 120 & 1.00 & 6.0 & 1.8 & 1.0 \\
\hline Duration of infertility & 120 & 1.00 & 22.0 & 5.5 & 4.5 \\
\hline
\end{tabular}

Table 2: Result of bivariate analysis between Chlamydia serology test and patients' social and gynaecological risk fact.

\begin{tabular}{|c|c|c|c|c|}
\hline \multicolumn{2}{|l|}{ Parameter } & Chlamydia serology negative & Positive & p-value \\
\hline \multirow{4}{*}{ Social economic status } & High & $29(24.2 \%)$ & $7(5.8 \%)$ & \multirow{4}{*}{0.040} \\
\hline & Middle & $20(16.7 \%)$ & $13(10.8 \%)$ & \\
\hline & Low & $27(22.5 \%)$ & $24(20.0 \%)$ & \\
\hline & Total & $76(63.3 \%)$ & $44(36.7 \%)$ & \\
\hline \multirow{4}{*}{ parity } & Nullipara & $45(37.5 \%)$ & $31(25.8 \%)$ & \multirow{4}{*}{0.043} \\
\hline & Primipara & $19(15.8 \%)$ & $3(2.5 \%)$ & \\
\hline & Multipara & $12(10.0 \%)$ & $10(8.3 \%)$ & \\
\hline & Total & $76(63.3 \%)$ & $44(36.7 \%)$ & \\
\hline \multirow{3}{*}{ Age at first sexual intercourse } & $\leq 18$ & $32(26.6 \%)$ & $34(28.3 \%)$ & \multirow{3}{*}{0.026} \\
\hline & $\geq 18$ & $44(36.7 \%)$ & $10(8.3 \%)$ & \\
\hline & Total & $76(63.3 \%)$ & $44(36.7 \%)$ & \\
\hline \multirow{3}{*}{ Type of infertility } & Primary & $30(25.0 \%)$ & $14(11.7 \%)$ & \multirow{3}{*}{0.261} \\
\hline & Secondary & $46(38.3 \%)$ & $30(25.0 \%)$ & \\
\hline & Total & $76(63.3 \%)$ & $44(36.7 \%)$ & \\
\hline \multirow{4}{*}{ Previous pelvic infection } & PID & $47(39.2 \%)$ & $26(21.7 \%)$ & \multirow{4}{*}{0.941} \\
\hline & STD & $2(1.7 \%)$ & $1(0.8 \%)$ & \\
\hline & None & $27(22.5 \%)$ & $17(14.2 \%)$ & \\
\hline & Total & $76(63.3 \%)$ & $44(36.7 \%)$ & \\
\hline
\end{tabular}

The prevalence of tubal factor infertility (bilateral tubal blockage on HSG) amongst the patients attending infertility clinic at Federal Medical Centre, Bida was 57 $(47.5 \%)$. The other factors responsible for infertility among the subjects were male factor (determined by seminal fluid analysis), contributing 31 (25.9\%), ovulatory factor (determined by midluteal progesterone) was responsible for $13(10.8 \%)$ while uterine factor determined by HSG findings contributed 6 (5\%). Combined male/female factors contributed 13 (10.8\%) as shown in Figure 1.

The prevalence of positive Chlamydia serology was 44 $(36.7 \%)$ among the patients studied. 


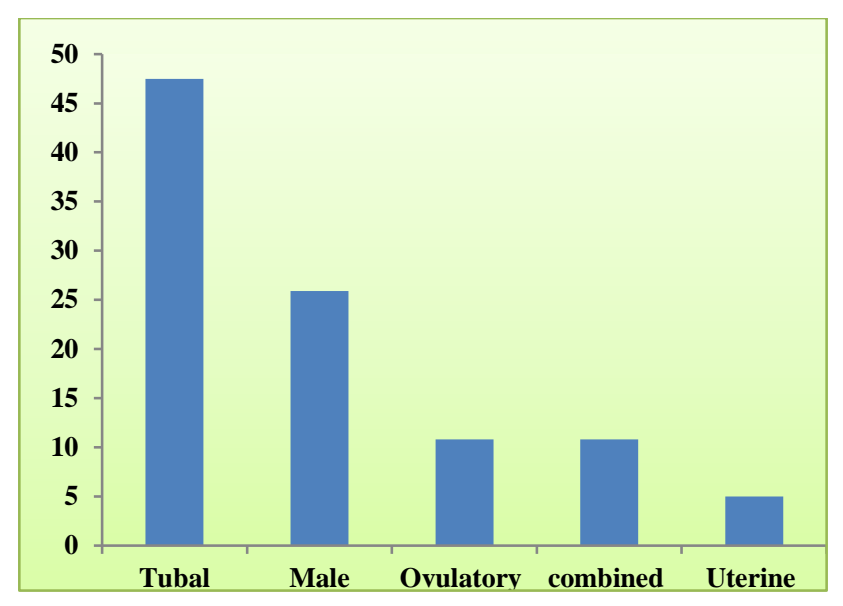

Figure 1: Distribution of causes of infertility.

However, among patients with tubal factor infertility, the prevalence of positive chlamydia serology was 34 $(59.6 \%)$ as against $10(15.9 \%)$ for non-tubal infertility as shown in Table 3. Chlamydia seropositivity was significantly associated with tubal factor infertility $(\mathrm{p}=0.01)$ as shown in Table 3.

Table 3: Association between Chlamydia serology test status and tubal infertility by HSG among women attending gynaecological clinics at the FMC, Bida, Niger state.

\begin{tabular}{|l|l|l|l|l|}
\begin{tabular}{|l|l|l|} 
Chlamydia \\
Serology
\end{tabular} & $\begin{array}{l}\text { Unblocked } \\
\mathbf{N = 6 3} \\
\mathbf{n}(\boldsymbol{\%})\end{array}$ & $\begin{array}{l}\text { Blocked } \\
\mathbf{N = 5 7} \\
\mathbf{n}(\boldsymbol{\%})\end{array}$ & $\chi^{2}$ & p \\
value \\
\hline Positive & $10(15.9)$ & $34(59.6)$ & 18.09 & $<0.01 *$ \\
\hline Negative & $53(84.1)$ & $23(40.4)$ & & \\
\hline *p value $<0.05$ is significant. & & & \\
\hline
\end{tabular}

The accuracy of chlamydia serology test using HSG as the standard revealed moderate sensitivity and negative predictive values at $59.6 \%$ and $69.7 \%$ respectively. The specificity and positive predictive values were high at $84.1 \%$ and $77.2 \%$ respectively. The positive and negative likelihood ratios were 3.7 and 0.48 respectively while the odds ratio for diagnosing tubal factor infertility with chlamydia serology was 7.8 as shown in Table 4.

Table 4: Diagnostic performance of Chlamydia serology test among women attending gynaecological clinics at the FMC, Bida, Niger state.

\begin{tabular}{|l|l|}
\hline Diagnostic parameters & Value \\
\hline Sensitivity & $59.6 \%$ \\
\hline Specificity & $84.1 \%$ \\
\hline Positive predictive value & $77.2 \%$ \\
\hline Negative predictive value & $69.7 \%$ \\
\hline Positive likelihood ratio & 3.7 \\
\hline Negative likelihood ratio & 0.48 \\
\hline Diagnostic odds ratio & 7.8 \\
\hline
\end{tabular}

\section{DISCUSSION}

This study demonstrated that chlamydial serology was useful in predicting tubal factor infertility. This result was similar to what was observed in other studies done by Surana and co-workers, Debakausen et al, and Koledade. ${ }^{17,18,26}$ Akande and Lardenoije also found similar pattern in Europe. This is due to universal prevalence of chlamydia trachomatis infection and its asymptomatic nature.

The prevalence of tubal factor infertility from this study was $47.5 \%$. This was not surprising as tubal factor is the leading cause of infertility in low resource settings like Nigeria. The finding of this study was in agreement with works done in various parts of the country that consistently depicted tubal factor infertility as the major cause of infertility. The prevalence found were $39.5 \%$, $46.1 \%, 67.2 \%$ and $49.0 \%$ in South-west, North-east, North-west and South-eastern Nigeria respectively. ${ }^{4,27-29}$ These high prevalence are the sequelae of untreated or poorly treated pelvic infections $(62.7 \%)$ in this study. However, in developed countries the major contributor to infertility was ovulatory accounting for about $27 \% .^{30}$ Infective causes are much less in developed countries hence tubal factor played a less significant role, contributing about $15 \%$ to infertility. ${ }^{2}$

The prevalence of positive Chlamydia serology in this study was $36.7 \%$ and the finding was in agreement with some studies in Nigeria and other West-African countries were the prevalence of positive chlamydial antibody test ranged from $20.5 \%$ to $39.0 \% .^{8,9,31,32}$ This might be due to the similarities in the socio-demographic features of the population studied. However, the prevalence of $65.8 \%$ $74 \%$ found in South-South studies were higher than the prevalence in this study. ${ }^{7,32}$ This might be connected with the sexual behavioural practices linked with Chlamydia infections.

In this study, the mean age at first sexual intercourse was $19.8 \pm 4.9$ years as against $17 \pm 3.6$ years in one of the South-South studies. ${ }^{7}$ In two of the South-South studies, the life time number of sexual partners were three or more as against 1.8 in this study. The higher prevalence in the South-south studies compared to this study may be due to difference in sexual behavioural practices in these geopolitical zones. ${ }^{7,26,32}$

Among the subjects with tubal factor infertility, 59.6\% were positive for chlamydia serology as against $15.9 \%$ positive chlamydia serology among patients with nontubal infertility. The difference in the prevalence of positive chlamydial serology in tubal and non-tubal infertility further highlights the role of chlamydia trachomatis in the aetiopathogenesis of tubal infertility. ${ }^{12}$ The prevalence of chlamydia seropositivity found in this study was similar to that $(64.2 \%)$ found in a Benin study by Omo-Aghoja and co-workers. ${ }^{7}$ 
The test of association between chlamydia seropositivity and tubal factor infertility was statistically significant $(p<0.05)$. This finding lends credence to the strong association between chlamydia seropositivity and tubal factor infertility as had been demonstrated by several other studies. Koledade and co-workers found that recent and previous chlamydia infection were both associated with tubal infertility. ${ }^{8,18,26,33,34}$ However this study did not look at recent chlamydia infection. In Calabar Southsouth Nigeria, Odusolu and co-workers found that the prevalence of C. trachomatis $\mathrm{IgG}$ antibody was $38.6 \%$ in the infertile women and was statistically significant $(p<0.05)$ with infertility. ${ }^{35}$ Akande and Lardenoije in UK and Netherlands found that chlamydia antibody positivity was significantly associated with tubal infertility. ${ }^{33,34}$ In South-South Nigeria, Omo-Aghoja and co-workers attempted to associate chlamydia trachomatis serology with tubal infertility and found no strong independent association between chlamydia antibodies and the risk of being infertile in Nigeria women. ${ }^{7}$ This is the only study from available literature that did not agree with the findings of this work, this may be due to methodological difference since their work was quantitative (titre) and not qualitative.

The socio-demographic risk factors found in this study to influence the prevalence of positive chlamydia serology and tubal factor infertility was low socio-economic status (as determined by Okpere and coworkers) which has been

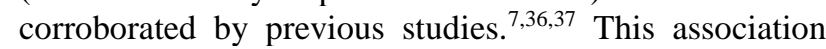
might be due to inability to afford basic health care, poor health seeking behaviour. Though this study did not probe into health seeking behaviour of subjects, other studies have suggested that women from low socioeconomic status were more likely to seek ineffective treatment from chemists and other unorthodox medical practitioners than obtain effective evidence based treatment from qualified practitioners. ${ }^{7}$ The sexual and reproductive risk factors that were significant in this study included nulliparity and early age at first sexual intercourse. All these have been found by other workers to contribute to tubal infertility since they were essential recipe for PID with attendant tubal damage. $7,9,15$

Table 4 shows that Chlamydia serology test had a sensitivity of $59.6 \%$ that is the probability that the test will detect disease (tubal infertility) among those with the disease while the probability of the test being negative when the disease is absent (specificity) was $84.1 \%$. The positive predictive value was $77.2 \%$ showing the probability of the disease being present when the test is positive while the probability of the absence of disease with a negative result (negative predictive value) was $69.7 \%$. The positive and negative likelihood ratios were 3.7 and 0.48 respectively showing that positive chlamydia serology test significantly increases the probability of tubal infertility and negative chlamydia serology test significantly decreases the probability of disease. The diagnostic odds ratio of 7.8 shows the test has good discriminative ability among those with and without tubal infertility.

The accuracy of Chlamydial serology using HSG as the standard was found to be highly specific as well good positive predictive value. ${ }^{8}$ This implies that a positive chlamydia serology test is highly indicative of tubal blockage and might be a good alternative for tubal patency assessment. ${ }^{18,26,34,38}$ However, chlamydia serology test was found to moderate sensitivity and moderate negative predictive value, this implies that negative chlamydial serology does not rule out the possibility of tubal blockage. This is similar to the findings of other workers who found chlamydia serology to have high specificity and positive predictive value but low sensitivity and negative predictive value. ${ }^{8}$ This finding might be as a result of tubal spasm suggesting tubal blockage, giving a false positive result. This challenge would have been resolved by the use of laparoscopy and dye test but that was outside the scope of this study. Comparing laparoscopy and chlamydia serology might be a better alternative to ascertaining the accuracy of serological screening test and could be a point for future research. In fact Debakausen and coworkers have reported that chlamydia antibody testing is more accurate than HSG in predicting tubal factor infertility, the odds for predicting tubal infertility with chlamydia antibody was 9.1 as against 2.6 with HSG. ${ }^{18}$ The odds ratio in this study was approaching that of Debakausen.

Chlamydia IgG kit cost an average of $\$ 3$ per kit, while HSG is about $\$ 30$ or more in most centres. This is quite significant in a resource poor setting and a country grappling with recession like Nigeria. Therefore, chlamydia serology may be a substitute for HSG in screening for tubal infertility. However, confounders like endometriosis, previous pelvic surgery, non-chlamydia causes of PID, peritonitis must first be ruled out.

The limitations of this study included its inability to distinguish the various sources of tubal pathology; for example, micro-organisms other than C. trachomatis, peritonitis, endometriosis and previous pelvic surgery, though attempt was made at excluding some of them. More so, the kit used was qualitative giving either positive or negative result. A quantitative test that determines the titre level may be more accurate in distinguishing titre levels and their correlation with tubal damage or severity of disease. The kit also cannot distinguish tubal blockage secondary to tubal spasm thus affecting the specificity.

\section{CONCLUSION}

This study revealed high prevalence of previous chlamydia infection in patients with tubal infertility and a strong association between chlamydia seropositivity and tubal factor infertility. 
Therefore, Chlamydia serology is useful in predicting tubal factor infertility and should be incorporated in the routine work up for infertility, the result of which might influence decision on further investigations.

\section{Recommendations}

Based on the findings of this study, it may therefore be recommended that Chlamydia serology test should be incorporated into routine infertility work up as a screening test for tubal factor infertility. There should be massive public enlightenment on the consequences of pelvic infection and the need for prompt and adequate treatment to avert tubal infertility.

Funding: No funding sources Conflict of interest: None declared

Ethical approval: The study was approved by FMC Bida's Ethics and Research committee

\section{REFERENCES}

1. Fard SA, Ebrahimi FS, Montazeri F, Mashrabi O. Diagnostic features and therapeutic consequences of hysteroscopy in women with abnormal uterine bleeding and abortion. Am J App Sci. 2012;9(1):137.

2. Abma JC, ed. Fertility, family planning, and women's health: new data from the 1995 National Survey of Family Growth. National Ctr for Health Statistics; 1997.

3. Abolfotouh MA, Alabdrabalnabi AA, Albacker RB, Al-Jughaiman UA, Hassan SN. Knowledge, attitude, and practices of infertility among Saudi couples. Int J Gen Med. 2013;6:563-73.

4. Adams A, Sharpe A. Infectious diseases. In: Kuma FNV, Abbas AK, eds. Robbins and Cotran pathological basis of disease. $7^{\text {th }}$ ed. Philadelphia: Elsevier Sanders. 2005:343-414.

5. Akande VA, Hunt LP, Cahill DJ, Caul EO, Ford WC, Jenkins JM. Tubal damage in infertile women: prediction using chlamydia serology. Hum Reprod. 2003;18(9):1841-7.

6. Alfarraj DA, Somily AM, Alssum RM, Abotalib ZM, El-Sayed AA, Al-Mandeel HH. The prevalence of Chlamydia trachomatis infection among Saudi women attending the infertility clinic in Central Saudi Arabia. Saudi Med J. 2015;36(1):61.

7. Araoye M. Epidemiology of infertility: Social problems of the infertile couples. West Afr J Med. 2003;22(2):190-6.

8. Audu BM, Massa AA, Bukar M, El-Nafaty AU, Sa'ad ST. Prevalence of utero-tubal infertility. J Obstet Gynaecol. 2009;29(4):326-8.

9. Chernesky, M. The laboratory diagnosis of Chlamydia trachomatis infections. Can J Infect Dis. 2003;16(1):39-44.

10. Coppus SF, Opmeer BC, Logan S, Van der Veen F, Bhattacharya S, Mol BW. The predictive value of medical history taking and Chlamydia IgG ELISA antibody testing (CAT) in the selection of subfertile women for diagnostic laparoscopy: a clinical prediction model approach. Hum Reprod. 2007;22(5):1353-8.

11. Dattijo LM, Andreadis N, Aminu BM, Umar NI, Black KI. The prevalence and clinical pattern of infertility in Bauchi, northern Nigeria. Trop J Obstet Gynaecol. 2016;33(1):76-85.

12. Dabekausen YA, Evers JL, Land JA, Stals FS. Chlamydia trachomatis antibody testing is more accurate than hysterosalpingography in predicting tubal factor infertility. Fertil Steril. 1994;61(5):8337.

13. Etuk SJ. Reproductive Health: Global Infertility Trend. Niger J Physiol Sci. 2009;24(2):85-90.

14. Gerias A, Rushman H. Infertility in Africa. Popul Sci. 1992;12:25-46.

15. Ikechebelu JI, Adinma JI, Orie EF, Ikegwuonu SO. High prevalence of Male infertility in South eastern Nigeria. J Obstet Gynaecol. 2003;23(6):657-9.

16. Jain $M$. Correlation between the serum antichlamydial antibodies and tubal factor infertility. J Obes Gynec Lnd. 1993;43(3):380-4.

17. Jeremiah I, Okike O, Akani C. The prevalence of Serum Immunoglobulin G Antibody to Chlamydia trachomatis in Subfertile Women Presenting at the University of Port Harcourt Teaching Hospital. Int J Biomed Sci. 2011;7(2):120-4.

18. Kish L. Survey Sampling. New York. 1965.

19. Koledade AK, Adesiyun AG. Investigation Correlates of Chlamydia antibody testing and Hysterosalpingography among women with tubal infertility. Open J Obstet Gynecol. 2014;4(16):1077.

20. Lardenoije C, Land J. Chlamydia antibody testing for tubal factor infertility. Ned Tijdschr Geneeskd. 2007;151(36):1981-5.

21. Machado AC, Guimarães EM, Sakurai E, Fioravante FC, Amaral WN, Alves MF. High Titers of Chlamydia trachomatis Antibodies in Brazilian Women with tubal occlusion or Previous Ectopic pregnancy. Infect Dis Obstet Gynecol 2007;2007.

22. Mardh P. Tubal factor infertility with special regards to chlamydial salpingitis. Curr Opin Infect Dis. 2004; 17:49-52.

23. Mol BW, Dijkman B, Wertheim P, Lijmer J, van der Veen F, Bossuyt PM. The accuracy of chlamydial antibodies in the diagnosis of tubal pathology: a meta-analysis. Fertil Steril. 1997;67(6):1031-7.

24. Morhason-Bello IO, Ojengbede OA, Oladokun A, Adedokun BO, Ajayi A, Adeyanju AA, et al. The prevalence and outcome of asymptomatic chlamydia infection screening among infertile women attending gynaecological clinic in Ibadan, South Western Nigeria. Ann Med Health Sci Res. 2014;4(2):253-7.

25. Odusolu P, Edet E, Emechebe C, Agan T, Okpe A. Prevalence of Chlamydia trachomatis immunoglobulin $\mathrm{G}$ antibody in infertile women in Calabar. Afr J Med Health Sci. 2016;15(2):74-9. 
26. Olusanya $\mathrm{O}$. The importance of social in voluntary fertility control in a developing country. West Afr J Med. 1985;4:205-12.

27. Omo-Aghoja LO, Okonofua FE, Onemu SO, Larsen U, Bergstrom S. Association of Chlamydia trachomatis serology with tubal infertility in Nigerian women. J Obstet Gynaecol Res. 2007;33(5):688-95.

28. Sharma S, Mittal S, Aggarwal P. Management of infertility in low resources countries. BJOG. 2009;116:77-83.

29. Siemer J, Theile O, Larbi Y, Fasching PA, Danso KA, Kreienberg R, et al. Chlamydia trachomatis infection as a risk factor for infertility among women in Ghana, West Africa. Am J Trop Med Hyg. 2008;78(2):323-7.

30. Siladitya Bhattacharya. Infertility. In: Keith Edmonds, ed. Dewhurt's Textbook of Obstetrics and Gynaecology. $7^{\text {th }}$ ed. Blackwell: Oxford University Press; 2007:440-460.

31. Gold immunofiltration rapid test for Chlamydia trachomatis $(\operatorname{IgG} / \operatorname{IgM})$. Available at: www.spanbio.com.E-mailinfo@spanbio.com.

32. Stary A. Chlamydia Screening which sample for which technique?. Genitourin Med. 1997;73(2):99102.

33. Surana A, Rastogi V, Nirwan PS. Association of the Serum Anti-chlamydial Antibodies with Tubal Infertility. J Clin Diagn Res. 2012;6(10):1692-4.
34. Thomas K, Coughlin L, Mannion PT, Haddad NG. The value of chlamydia trachomatis antibody testing as part of the routine infertility investigation. Hum Reprod. 2000;15(5):1079-82.

35. Torrone E, Papp J, Weinstock H. Centers for Disease Control and Prevention (CDC). Morb Mortal Wkly Rep. 2014:834-8.

36. Tukur J, Shittu SO, Abdul AM. A case control study of active genital chlamydia trachomatis infection among patients with tubal infertility in Northern Nigeria. Trop Doct. 2006;36(1):14-6.

37. World Health Organization. Infections, pregnancies and infertility: Perspectives and Prevention. Fertil Steril. 1987;47(6):964-8.

38. World Health Organization (WHO). Mother or nothing: The agony of infertility. WHO Bulletin. 2010;88:877-953.

Cite this article as: Amadi L, Onwudiegwu U, Adeyemi AB, Nwachukwu CND, Abiodun AB. Usefulness of Chlamydia serology in prediction of tubal factor infertility among infertile patients at Federal Medical Centre, Bida, North Central Nigeria. Int J Reprod Contracept Obstet Gynecol 2019;8:4129. 